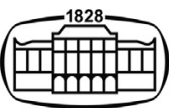

AKADÉMIAI KIADÓ

\title{
Face validity evaluation of screening tools for gaming disorder: Scope, language, and overpathologizing issues
}

\section{Journal of Behavioral Addictions}

9 (2020) 1, 1-13

\section{DOI:}

$10.1556 / 2006.2020 .00001$ (c) 2020 The Author(s)

\section{REVIEW ARTICLE}

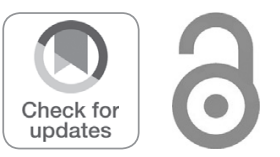

\section{DANIEL L. KING ${ }^{1,6 *}$ (D), JOEL BILLIEUX ${ }^{2,3}$, NATACHA CARRAGHER ${ }^{4,5}$, and PAUL H. DELFABBRO ${ }^{6}$}

${ }^{1}$ College of Education, Psychology, \& Social Work, Flinders University, Adelaide, Australia

${ }^{2}$ Institute of Psychology, University of Lausanne, Lausanne, Switzerland

${ }^{3}$ Addictive and Compulsive Behaviors Lab, Institute for Health and Behavior, University of Luxembourg, Esch-sur-Alzette, Luxembourg

${ }^{4}$ Office of Medical Education, University of New South Wales (UNSW) Sydney, Australia

${ }^{5}$ Department of Mental Health and Substance Use, World Health Organization, Geneva, Switzerland

${ }^{6}$ School of Psychology, The University of Adelaide, Adelaide, SA, Australia

Received: October 19, 2019 • Revised manuscript received: December 11, 2019 • Accepted: December 25,2019 Published online: April 7, 2020

\begin{abstract}
Aim: Critics of gaming disorder (GD; i.e., Internet gaming disorder in the DSM-5; Gaming disorder in the ICD-11) have expressed concerns about the potential risks of misclassification (e.g., false positives). An important consideration of relevance to this discussion is the extent to which commonly used screening instruments contain appropriate, sensible, and relevant items. The aim of this review was to evaluate the face validity of items within current tools for GD. Methods: A systematic review of databases identified 29 instruments. An item bank ( $n=417$ items) was independently evaluated by three professional raters (i.e., a senior academic in clinical psychology, a senior psychometrician, and an academic/clinical psychologist) according to guidelines for defining and measuring addiction and gaming disorder. Findings: Evaluation of the item bank identified issues related to: scope (i.e., "scope creep" or items of questionable relevance); language (i.e., confusing language, unusual wording or syntax); and overpathologizing (i.e., pathologizing typical and/or beneficial aspects or consequences of gaming). A total of 71 items across 23 tools had at least one face validity issue. Conclusions: Most items (83\%) demonstrated satisfactory face validity and were consistent with either the DSM-5 or ICD-11 GD classification. However, many tests contain at least one item that may pathologize normal gaming behaviors. Such items refer to basic changes in mood when gaming, a desire to play or continue playing games, and experiencing immersion when gaming. This analysis highlights the challenges of screening for problematic behaviors that are thought to arise within the context of normal recreational activities.
\end{abstract}

\section{KEYWORDS}

Internet gaming disorder, gaming disorder, screening, assessment, face validity, overpathologizing

\section{INTRODUCTION}

Gaming disorder (GD) has been officially recognized in the eleventh edition of the International Classification of Diseases (ICD-11; WHO, 2019), following the recognition of "Internet gaming disorder" as a condition for further study in Section III of the DSM-5 (American Psychiatric Association, 2013). These developments have followed the publication of numerous studies of this condition, including epidemiological studies, neurobiological research, and interventions (Brand, Young, Laier, Wölfling, \& Potenza, 2016; Feng et al., 
2017; Saunders et al., 2017; Stevens, King, Dorstyn, \& Delfabbro, 2019). In this literature, research participants have often been classified or assigned to groups of "addicted" or "disordered" gamers using one of the many available screening instruments that have been created over the last two decades (King et al., 2020). Some commentators have criticized the evidence as "weak" (van Rooij et al. 2018, p. 6), and raised concerns about the risk of misclassification (Starcevic, 2017). These concerns often cite the notion that the disorder would "stigmatise" and create "moral panic" (Aarseth et al., 2017; Bean, Nielsen, Van Rooij, \& Ferguson, 2017) about a common class of behavior that may not be inherently harmful for the majority of participants.

Along similar lines, researchers who support GD have noted that the bar should be set reasonably high to avoid viewing "regular" or recreational behavior as a problem (King, Delfabbro, Potenza, Demetrovics, Billieux, \& Brand, 2018b, King, Herd, \& Delfabbro, 2018a). This distinction is particularly relevant to a condition such as GD given that there are many people who would identify as "highly engaged" in the activity (Billieux, Flayelle, Rumpf, \& Stein, 2019). These individuals may report spending a lot of time thinking about games and seeking out new gaming opportunities but do not experience negative consequences related to their recreational participation in gaming activities (King \& Delfabbro, 2014). For such players, the positives of gaming may largely outweigh any negatives (which may be minor). Thus, it is important, from a research, clinical, and public health perspective, that screening measures are not overly sensitive and do not misclassify these individuals as problematically involved or "addicted" to games (Ko, Lin, Lin, \& Yen, 2019; Rumpf et al., 2018).

Previous reviews have noted some inconsistencies and psychometric weaknesses in instrumentation (King, Haagsma, Delfabbro, Gradisar, \& Griffiths, 2013; Petry et al., 2014). These reviews have tended to focus on important psychometric considerations, such as factorial structure, reliability, and correlates (convergent and divergent validity). Such evidence is critical to determining the psychometric performance of the test, including whether these measures can reliably differentiate between clinical and normal or recreational behavior (what is sometimes referred to as criterion validity). If such validation does not exist, then the scores obtained on these scales will merely reflect the nature of the items included which may ultimately produce inflated prevalence rates of harm. In support of this view, there have been multiple studies of adolescents that report gaming disorder figures that exceed $20 \%$ which seem to defy common sense or logic, and which likely include a high number of false positives (Sosso et al., 2020; Seok \& DaCosta, 2012; Wang, Chan, Mak, Ho, Wong, \& Ho, 2014; Xin, Xing, Pengfei, Houru, Mengcheng, \& Hong, 2018).

One way to evaluate new instruments is to consider the extent to which the content of test items matches the clinical description of the condition (i.e., face validity). While face validity is not considered to be the optimal indicator of a test's quality, it can nevertheless be beneficial as a preliminary check. A face validity evaluation of test items is usually undertaken in the early stages of test construction, typically by a small group of independent raters (Holloway et al., 2014). Although this approach is subjective and depends largely on the views and interpretation of each panel member and the panel composition itself (Campbell, Hann, Roland, Quayle, \& Shekelle, 1999), face validity checks may have beneficial outcomes (e.g., identify potential problems with test items that can then be reviewed psychometrically). This is particularly so when undertaken by a panel of experts or individuals with personal experience, especially for tests of new conditions or tests containing previously unexamined scale items (Hardesty \& Bearden, 2004).

This review examines the extent to which the items included in prevailing GD tests appear to be consistent with current criteria and descriptions of the condition. This paper employs the acronym GD to encompass both the DSM-5 and ICD-11 classifications, including the symptoms of the condition. This review involved a systematic search to identify all currently used tests and then a panel evaluation of all test items to identify any potential face validity issues. This evaluation was primarily intended to identify items that may benefit from further examination and should not be viewed as objective evidence of the strengths or weaknesses of any given test highlighted in this analysis. However, as the field of behavioral addictions appears to be expanding its scope, it is important to identify and avoid potentially problematic items being transposed to other proposed conditions that have similarities to gaming behaviors. Many of the first tools for problematic gaming and/or GD were created by adapting measures of pathological gambling and substance use disorders (King \& Delfabbro, 2019); similarly, measurement approaches to other problematic online behaviors (e.g., social media use) have been guided by those used for GD (e.g., Besser, Loerbroks, Bischof, Bischof, \& Rumpf, 2019).

\section{METHODS}

\section{Identification of Screening Tools}

This review aimed to evaluate all available screening tools for GD published in English. A search of Google Scholar and academic databases, including PsychINFO, Academic Search Complete, ScienceDirect, PubMed and Web of Science (search date: 4/4/2019), yielded 3,499 results (including duplicate results). The following keywords and protocol were used: (video game OR gam ${ }^{\star}$ ) AND (tool OR measure OR test OR validation OR psychometric OR screening OR diagnos ${ }^{\star}$ OR item OR instrument). A list of tools was generated by identifying tests in the methodology section of empirical studies. Excluded tests included: composite tests (i.e., two or more tests combined into one); established tests or criteria with modified or added items; and tests without a citation or full text. Internet use-related tests (e.g., Young Internet Addiction Test) were included if they had been employed in studies to measure GD symptoms. Other relevant reviews (King et al., 2013; Lortie \& Guitton, 2013; Petry et al., 2014) 
were also consulted to assist in identifying relevant tools The Google Scholar citation lists of all original sources $(N=$ 12,996 citations) were checked for any additional tests, which included 320 empirical studies. In total, 29 tools were identified. From these tools, an item bank of 417 items was produced for evaluation.

\section{Item Evaluation}

All 417 items were evaluated by three professional raters (i.e., a senior academic in clinical psychology, a senior psychometrician, and an academic/clinical psychologist). The objective of this analysis was to identify items that appeared problematic on face value, and to then reach a panel consensus rating on these items. A scoring sheet was assigned to each rater who completed the sheet blinded to the other two raters' responses.

The aim of the face validity evaluation of each item was to consider whether: (1) the item matches its respective criterion: whether the item's wording was consistent with the construct and concepts of addiction, such as impaired control (Goodman, 1990; Griffiths, 2017; West, 2001), and/or descriptions of gaming disorder or addiction according to the DSM-5 and/or ICD-11 (Grant and Chamberlain, 2016; King \& Delfabbro, 2019); (2) the item refers to a harmful or distressing experience; whether the item referred to a gaming behavior that is distressing, risky or harmful to the user and/or others (Stein, Phillips, Bolton, Fulford, Sadler, \& Kendler, 2010), and excluded behaviors or consequences that would generally be considered normal or adaptive (Billieux et al., 2017; Kardefelt-Winther et al., 2017); and (3) the item is clear and easily understood: whether the item employed clear and unambiguous language (Willis, 2004). The above considerations informed the development of a scoring sheet (Excel spreadsheet) with five categories: scope, language, overpathologizing, lacking clinical relevance, and other.

Initial ratings of the item bank (i.e., 5 categories $\times 417$ items $=2,085$ individual items) were collated, with the following rater discrepancies noted: 219 problematic items (10.5\%) according to one rater (with 43 or $2.1 \%$ of these items rated as having another unanimously rated validity issue), and 88 problematic items (4.2\%) according to two raters. A second evaluation round involved all three raters re-evaluating the 88 items with 2 positive ratings, with the option to provide reasoning for each decision. The re-evaluation led to 41 items endorsed by two raters changed to unanimous agreement, and 47 items unchanged. There was no clear pattern to non-unanimous ratings according to the five categories, but one particular two-rater combination (DLK and JB) was more inclined to critique items across all five categories ( $n=30$ were left non-unanimous). Items with single rater-identified issues were not re-evaluated. The most common issue that was identified by a single rater related to "lacking clinical relevance" ( $n=79$ or $36 \%$ ), and $n=25$ of these same items were unanimously endorsed as "overpathologizing", suggesting that there was some overlap in the perception of these two categories. Internal discussion suggested that some of the inconsistent agreement on "lacking clinical relevance" related to differing views of the utility of some items for gathering useful information about the severity of gaming-related problems.

Only items with total agreement from all three raters were included in the analysis. It was reasoned that, given the subjectivity inherent to face validity evaluation (as highlighted by the discrepancies reported above), it was optimal to exclude items that did not elicit unanimous agreement in a small professional group. For a review of this kind, the objective was to present the stronger examples of potential face validity issues. Included items were discussed by the panel after their individual evaluations to check and confirm scores and reasoning. A table summarizing the group's reasoning was created. The evaluation was conducted without referring to other test information that might influence judgment (e.g., practical considerations and psychometric properties, supporting evidence base). For example, whether an item was internally consistent with other items was not relevant. The problematic aspects of items have been underlined, where necessary, for ease of reporting results. All results are presented in complete detail in tables for transparency.

\section{RESULTS}

Table 1 presents the item evaluation for 23 tests with face validity issues, including the test name, item wording, and rationale for inclusion. In total, face validity issues were identified across 71 items. Items were grouped into one of three categories that referred to its primary limitation. These limitations included: scope (i.e., "scope creep" or items of questionable relevance); language (i.e., confusing language, unusual wording or syntax); overpathologizing (i.e., pathologizing typical and/or beneficial aspects or consequences of gaming), and other issues (i.e., low level harms and "discordant" items that do not match the symptom area).

Table 2 presents a summary of the total face validity issues for each test. Overall, most tests had very few items with face validity issues. The four tests with the highest proportion of face validity issues were the VASC (52\%) (Yilmaz, Griffiths, \& Kan, 2017), POGU (45\%) (Kim \& Kim, 2010), POGQ-SF (25\%) (Papay et al., 2013), and the YIAT (25\%) (Young, 1998a,b). It should be noted that these percentages encompass items with different concerns and thus should not be considered as comparable ratings. Further, certain issues (e.g., overpathologizing) may be more serious than others (e.g., questionable clarity) and therefore these ratings are unweighted.

Based on citation records, these four tests have been employed in 71 empirical studies (or, $21 \%$ of empirical studies that have employed the 29 tests). This literature primarily involved the YIAT ( $n=62$ studies), which includes 31 studies that have used the tool to assist in identifying clinical samples, followed by the POGQ-SF (6 studies), POGU (2 studies), and VASC (1 study). The authors of these studies have generally not expressed any 


\begin{tabular}{|c|c|c|}
\hline Tool & Item $^{*}$ & Reason \\
\hline \multirow[t]{2}{*}{ A-EQ (Charlton \& Danforth, 2007) } & I never miss meals because of Internet gaming. & $\begin{array}{l}\text { Confusing: Negative phrasing creates a generalization. } \\
\text { Skipping one meal yields an affirmative answer. }\end{array}$ \\
\hline & $\begin{array}{l}\text { I have never used Internet gaming as an } \\
\text { escape from socializing. }\end{array}$ & $\begin{array}{l}\text { Confusing: Negative phrasing creates a generalization. } \\
\text { Overpathologizing: Escape is not problematic } \\
\text { if not associated with negative consequences. }\end{array}$ \\
\hline \multirow[t]{2}{*}{ AICA-S (Wölfling et al., 2012) } & $\begin{array}{l}\text { How strongly are your thoughts involved with } \\
\text { playing computer games? }\end{array}$ & $\begin{array}{l}\text { Confusing: The meaning of "thoughts involved" } \\
\text { may be unclear. }\end{array}$ \\
\hline & $\begin{array}{l}\text { How often do you play computer games, although you resolved not to do so } \\
\text { or did you play more often or, respectively, longer than you had intended? }\end{array}$ & $\begin{array}{l}\text { Confusing: Multiple parts and complicated } \\
\text { logic/syntax may create some uncertainty. }\end{array}$ \\
\hline \multirow[t]{3}{*}{ CSAS (Rehbein et al., nd) } & Games are on my mind, even at times when I'm not playing. & $\begin{array}{l}\text { Overpathologizing: Not unusual to think about } \\
\text { hobbies even not involved in them. }\end{array}$ \\
\hline & I feel that games are becoming more and more important to me. & $\begin{array}{l}\text { Overpathologizing: May refer to becoming } \\
\text { more interested in a new hobby. }\end{array}$ \\
\hline & Playing games is the best way for me to forget about my problems. & $\begin{array}{l}\text { Overpathologizing: Gaming to forget problems } \\
\text { is not inherently a problem. }\end{array}$ \\
\hline \multirow[t]{2}{*}{ DIA (Ryu et al., 2019) } & $\begin{array}{l}\text { Do you have a strong desire to do activities such as internet/ Games/SNS? If } \\
\text { you want to play internet/Games/SNS, is it hard to tolerate? }\end{array}$ & $\begin{array}{l}\text { Confusing: Multiple parts and complicated } \\
\text { logic/syntax may create some uncertainty. }\end{array}$ \\
\hline & $\begin{array}{l}\text { Do you want to spend more Internet/Gaming/SNS time, find more } \\
\text { interesting things, or use better equipment such as cell phones, } \\
\text { computers to make you feel as fun as before? }\end{array}$ & $\begin{array}{l}\text { Confusing: Multiple parts and complicated } \\
\text { logic/syntax may create some uncertainty. }\end{array}$ \\
\hline GAIT (Vadlin et al., 2015) & I often think about games or about gaming, even when I am not playing. & $\begin{array}{l}\text { Overpathologizing: Not unusual to think about } \\
\text { hobbies even not involved in them. }\end{array}$ \\
\hline \multirow[t]{5}{*}{ GAIA (Wong \& Hodgins, 2014) } & I miss my game character when I am unable to play video games. & $\begin{array}{l}\text { Scope: Not clear if distressing or generates low mood. } \\
\text { Missing a character may create positive self-reflection. } \\
\text { Not all games have distinct or persistent in-game characters } \\
\text { (e.g., mobile games, strategy games). }\end{array}$ \\
\hline & I often play video games to feel better. & Overpathologizing: Refers to a positive gaming experience. \\
\hline & I often play video games to release stress. & $\begin{array}{l}\text { Overpathologizing: Releasing stress may be a } \\
\text { positive or adaptive experience. }\end{array}$ \\
\hline & $\begin{array}{l}\text { I often play video games to change my mood, relax tension } \\
\text { or feel more excited. }\end{array}$ & $\begin{array}{l}\text { Overpathologizing: These experiences may be } \\
\text { positive or adaptive. }\end{array}$ \\
\hline & I often play video games to forget about my life outside of gaming. & $\begin{array}{l}\text { Overpathologizing: Games as entertainment } \\
\text { involve escaping from reality as part of the experience. }\end{array}$ \\
\hline GAS-7 (Lemmens et al., 2009) & Did you play games to forget about real life? & $\begin{array}{l}\text { Overpathologizing: Games as entertainment involve } \\
\text { escaping from reality as part of the experience. }\end{array}$ \\
\hline \multirow[t]{4}{*}{ GAS-21 (Lemmens et al., 2009) } & Do you spend much free time on games? & $\begin{array}{l}\text { Overpathologizing: Free time on gaming is } \\
\text { unlikely to cause interference. }\end{array}$ \\
\hline & Did you play longer than intended? & $\begin{array}{l}\text { Overpathologizing: Playing longer than intended may indicate } \\
\text { having fun and/or may occur without being harmful. }\end{array}$ \\
\hline & Did you play games to forget about real life? & $\begin{array}{l}\text { Overpathologizing: Games as entertainment } \\
\text { involve escaping from reality as part of the experience. }\end{array}$ \\
\hline & Have you played games to release stress? & (continued) \\
\hline
\end{tabular}


IGDT-10 (Király et al. 2017)

IGUESS (Jo et al., 2018)

Lemmens IGD-9 (Lemmens et al., 2015)

Lemmens IGD-27 (Lemmens et al., 2015)

POGU (Kim \& Kim, 2010)
Have you played games to feel better?

I never play games in order to feel better.

I have significantly increased the amount of time I play games over last year.

I usually think about my next gaming session when I am not playing.

I play games to help me cope with any bad feelings I might have.

\section{Do you systematically fail when trying to} control or cease your gaming activity?

Have you played to relieve a negative mood

(for instance helplessness, guilt, or anxiety)?

I play Internet games to remove or avoid negative feelings.

Have you felt unsatisfied because you wanted to play more?

Have you played games so that you would not have

to think about annoying things?

Have you felt unsatisfied because you wanted to play more?

Have you played games to forget about your problems?

Have you played games so that you would not

have to think about annoying things?

I feel unrestricted when playing online game.

I feel good and very interested while I play online game.

I experience a buzz of excitement while I play online game.

Playing online game is when I most feel pleasure.
Overpathologizing: Releasing stress may be a positive or adaptive experience.

Overpathologizing: Refers to a positive gaming experience. Confusing: Negative phrasing creates

an awkward generalization.

Overpathologizing: May be endorsed by people who have come to enjoy playing games more recently, or rediscovering gaming as a hobby.

Overpathologizing: Not unusual to think about hobbies even not involved in them. Lacking clinical relevance: Might refer to required planning for a complex game.

Overpathologizing: May refer to experiences of gaming as a positive coping strategy.

Confusing: "Systematically" is a complex word that may be unclear when referring to an individual's personal experiences, especially for adolescents.

Overpathologizing: Relieving negative mood may be positive or adaptive.

Overpathologizing: Relieving negative mood may be positive or adaptive. The alternative (playing games to experience negative feelings) is unlikely to be endorsed.

Overpathologizing: It is not uncommon or inherently problematic to desire more time involved in hobbies.

Overpathologizing: May capture temporary distraction or avoidance.

Overpathologizing: Wanting more may not necessarily be a negative experience.

Overpathologizing: May be adaptive for some users to play games occasionally to forget problems.

Overpathologizing: May be adaptive for some users to play games occasionally to redirect attention.

Scope: Refers to a psychological experience (feeling "unrestricted") outside of known problematic gaming processes. Confusing: Unrestricted has multiple meanings and interpretations. Overpathologizing: May refer to feeling uninhibited which may be positive.

Overpathologizing: Refers to a positive experience.

Overpathologizing: These experiences may be positive or adaptive. Overpathologizing: Refers to a positive experience. 
I find myself saying "just a few more minutes" when playing online game.

I feel intimate with people who I know from online game than people in reality.

I feel that many people playing online game acknowledge my skills than in real life.

People I met in online game are easier to understand than real life people.

POGQ (Demetrovics et al., 2012)

POGQ-SF (Pápay et al., 2013)

PVP Scale (Salguero \& Morán, 2002)

sIATgaming (Pawlikowski et al., 2013)

VASC (Yilmaz et al., 2017)
How often do you play longer than originally planned?

How often do you daydream about gaming?

How often do you lose track of time when gaming? How often do you feel time stops while gaming?

How often do you play longer than originally planned?

How often do you daydream about gaming?

How often do you lose track of time when gaming?

When I lose in a game or I have not obtained the desired results, I need to play again to achieve my target.

How often do you find yourself saying "just a few more minutes" when gaming?

I forget my problems while playing videogames.

In videogames, defeating my enemies/leaping up a level give me pleasure.

In videogames, defeating my enemies/leaping up a level makes me feel stronger than my enemies.

I think playing videogames is very enjoyable activity.

In videogames, defeating my enemies/leaping up a level increase my selfesteem.

I do not feel bored when I play videogames.

I feel happy when I play videogames.

I always talk about videogames with my friends.

I make friends via online videogames.

I see my videogames/game characters in my dreams.
Overpathologizing: Wanting more may

not necessarily be a negative experience.

Scope: May reflect relationship issues that extend beyond problematic gaming.

Scope: May reflect relationship issues that extend beyond problematic gaming. Overpathologizing: Social reinforcement

in large online games may be common for experienced players.

Scope: May reflect social anxiety, relationship issues or other developmental issues that are more primary

than problematic gaming symptoms.

Low level harm (Other): Playing longer than intended may indicate having fun and/or may occur without being harmful.

Overpathologizing: Daydreaming may be a positive experience

that does not interfere with daily activities.

Overpathologizing: Immersion in entertainment may be positive.

Overpathologizing: This may be a positive

experience of immersion.

Low level harm: Playing longer than intended may indicate having fun and/or may occur without being harmful.

Overpathologizing: Daydreaming may be a positive experience that does not interfere with daily activities.

Overpathologizing: Immersion in entertainment may be positive. Overpathologizing: The desire to replay a game

may be part of the enjoyment and not inherently problematic. Overpathologizing: The desire to keep playing

may be normative and positive.

Overpathologizing: Games as entertainment involve escaping from reality as part of the experience.

Overpathologizing: Refers to a positive gaming experience.

Overpathologizing: Refers to a positive gaming experience.

Overpathologizing: Refers to a positive gaming experience. Overpathologizing: Refers to a positive gaming experience.

Overpathologizing: Refers to a positive gaming experience. Overpathologizing: Refers to a positive gaming experience.

Overpathologizing: Refers to a positive social experience related to gaming.

Overpathologizing: Refers to a positive socia experience related to gaming. 
Overpathologizing: Dreaming about games may be a normal experience that does not cause distress or interference.

I act like videogame characters in my daily life activities.

VAT (van Rooij, Schoenmakers, Van den Eijnden, Vermulst, \& van de Mheen, 2012)

Do you think about gaming, even when you're not online?

Do you look forward to the next time you can game?

Do you think you should be gaming less often?

CIUS (Meerkerk et al., 2009)

Do you think about the Internet, even when not online?

Do you look forward to your next Internet session?

Do you think you should use the Internet less often?

YIAT (Young, 1998a,b)
How often do you prefer the excitement of the Internet to intimacy with your partner?

How often do you form new relationships with fellow online user?

How often do you check your email before

something else that you need to do?

How often do you find yourself anticipating

when you will go online again?

How often do you find yourself saying

"just a few more minutes" when online?
Scope: Not all games have distinct characters for player to relate to and imitate. Overpathologizing: Role-playing

may be a positive form of identity expression.

Overpathologizing: Not unusual to think about

hobbies even not involved in them.

Overpathologizing: May refer to positive

experience of anticipation.

Discordant (Other): Item refers to "preoccupation"

but appears to measure personal insight. Also assumes that the behavior is at a sufficiently high level to be problematic,

i.e., thinking one should spend less time gaming does not necessarily mean current use is excessive.

Overpathologizing: Not unusual to think about

hobbies even not involved in them.

Overpathologizing: May refer to positive experience of anticipation.

Discordant (Other): Item refers to "preoccupation"

but appears to measure personal insight. Also assumes that the behavior is at a sufficiently high level to be problematic i.e., thinking one should spend less time online does not necessarily mean current use is excessive.

Scope: May refer to relationship issues that extend beyond problematic gaming. Most activities (not just gaming) may be preferred over intimacy. Some respondents do not have partners.

Overpathologizing: May refer to a positive social gaming experience.

Scope: Refers to email which may not be relevant to gaming activities.

Overpathologizing: May refer to positive experience of anticipation.

Overpathologizing: The desire to keep playing may be normative and positive, and may be socially determined.

* Items may take the form of a statement or question. A-EQ: Addiction-Engagement Questionnaire; AICA-Sgaming. Assessment of Internet and Computer Addiction Scale-Gaming: CSAS: Video Game Dependency Scale; DIA: Diagnostic Interview for Internet Addiction; GAIT: Game Addiction Identification Test; GAIA: Game Addiction Inventory for Adults; GAS-7: Game Addiction Scale-7 items; GAS-21: Game Addiction Scale-21 items; IGD-20: Internet Gaming Disorder-20 Test; IGDS9-SF: Internet Gaming Disorder Scale-9 Short Form; IGDT-10; Internet Gaming Disorder Test-10 items; IGUESS: Internet Game Use-Elicited Symptom Screen; Lemmens IGD-9: Internet Gaming Disorder Scale-9 items; Lemmens IGD-27: Internet Gaming Disorder Scale-27 items; POGU: Problematic Online Game Use; POGQ: Problematic Online Gaming Questionnaire; POGQ-SF: Problematic Online Gaming Questionnaire-Short Form; PVP Scale: Problematic Video game Playing Scale; sIATgaming: Short Internet Addiction Test-Gaming; VASC: Video Game Addiction Scale for Children; VAT: Video Game Addiction Test; CIUS14: Compulsive Internet Use Scale-14 items; YIAT: Young Internet Addiction Test; YDQ: Young Diagnostic Questionnaire. 
concerns about these tests' validity, or their capability in identifying cases of GD, such as any inconsistency between test score and psychiatric evaluation or other adjunctive measure. Overall, the majority of available tests in the literature appear to be considered valid and reliable by the researchers who employed them, with the exception of Snodgrass et al. (2018) who reported that IGDS9-SF scores were not associated with CTRA, a leukocyte gene expression profile activated by chronic stress. The authors stated that "this may reflect the ineffectiveness of this measure...to adequately capture the experience of problematic gaming" (p. 11).

\section{Scope Issues}

Four tests (8 items) were identified in this category (i.e., GAIA, POGU, VASC, and YIAT). For example, the POGU refers to feeling intimate with other online players and feeling acknowledged by online players. Similarly, the YIAT refers to preferring gaming instead of intimacy with a partner, which is a forced choice question that may not necessarily centrally relate to gaming as the problem (i.e., this may relate to problems in the relationship unrelated to gaming). These items could be referring to psychological issues that fall outside the general category of addictive behavior and often may not be relevant. Similarly, the VASC refers to acting like a video game character in real life which may not be relevant to problematic gaming and/or to games that do not involve distinct playable characters (e.g., strategy games).

Suggested modifications. These tests may be improved by modifying items about relationship difficulties to be specifically related to gaming. Some tests could exclude items that refer to behaviors that are not included in the nomenclatural definitions of GD or, alternatively, score or weight these items separately (e.g., the C-VAT 2.0 and AICA-Sgaming do not count their items on "craving" and "daily time spent gaming", respectively, toward total addiction scores).

\section{Language Issues}

Another important issue was the use of items that employed unclear or unusual wording (9 items, 6 tests). Unclear and vague phrasing was evident in items with multiple parts (e.g., DIA: "Do you want to spend more gaming time, find more interesting things, or use better equipment such as cell phones, computers to make you feel as fun as before?") and in short items with ambiguous language (e.g., POGU: "I feel unrestricted when playing online game"; $A-E Q$ : "I feel a sense of power when I am Internet gaming"). The internal logic of some items was affected by unnecessary negative phrasing (e.g., IGD-20: "I never play games in order to feel better", "I know my main daily activity has not been negatively affected by my gaming"). The IGDS9-SF uses the adverb "systematically [fail]" which refers to a fixed plan to fail, usually in relation to a group or organization, which may be inappropriate for capturing unregulated behavior among individuals. The word "systematically" may also be less comprehensible for adolescents, a population that is often invited to complete gaming-related measures.

Suggested modifications. The wording of some tests/items might potentially be improved by reducing unnecessary or inconsistent words, including terms that refer to abstractions (e.g., "sense of power"). Replacing negative adverbs of frequency ("I never play...") with positive phrasing ("I play") may improve item sensitivity and provide a clearer measure of frequency.

\section{Overpathologizing Gaming}

A major problem identified across most tests (56 items, 20 tests), and which has been raised by researchers who criticize gaming disorder as a mental disorder (Aarseth et al., 2017; Bean, Nielsen, Van Rooij, \& Ferguson, 2017; Billieux, Schimmenti, Khazaal, Maurage, \& Heeren, 2015; Przybylski, Weinstein, \& Murayama, 2016; van Rooij et al., 2018), is the potential for tests to "overpathologize" normal and adaptive gaming behaviors and consequences. The VASC was found to include 11 items that refer to the benefits of gaming (e.g., "I think playing video games is a very enjoyable activity"; "I feel happy when I play video games"; "I always talk about video games with my friends"). These items are counted toward a total score, based on 21 items, to indicate "possible addiction" (Yilmaz et al., 2017, p. 873). Further, the VASC has a cut-off score of 90 out of a possible 105, and therefore the test requires that individuals endorse items referring to benefits of gaming in order to be considered "addicted" (i.e., endorsing only the harm-related items [e.g., "I cannot resist playing videogames even if it negatively affects my life"; "I have sleeping problems due to playing videogames"] is insufficient to be considered a problematic gamer). Similar problems of pathologizing the benefits of gaming arise in other tests to a lesser extent (i.e., these items are not required to meet the cut-off but they would nevertheless inflate total scores in the distribution). Some examples include: GAIA: "I often play video games to release stress"; POGU: "I feel good and very interested while I play online game"; VAT: "Do you look forward to the next time you can game?".

Some items appear to be based on an assumption that having any level of interest in games, or valuing games as a hobby, is inherently risky (e.g., CSAS: "I feel that games are becoming more and more important to me"; GAS-21: "Do you spend much free time on games?"). Immersion effects and losing track of time while engaged in gaming, which may be a consequence of normal enjoyment or "flow" (Csikszentmihalyi, 1997), is similarly considered problematic (e.g., POGQ: "How often do you feel time stops while gaming?", "How often do you lose track of time when gaming?; POGU: "I feel a buzz of excitement while I play online game"). The IGD-20 conflates a factual statement about the time requirement associated with goals in games with a symptom of addiction (i.e., "I often think that a whole day is not enough to do everything I need to do in-game"), which would be true of many modern video games, 
Table 2. Overall evaluation of the face validity of gaming disorder (GD) screening tools $(n=29)$

\begin{tabular}{|c|c|c|c|c|c|c|c|c|c|c|c|c|c|c|c|c|c|c|c|c|c|c|c|c|c|c|c|c|c|c|}
\hline Face validity issues & 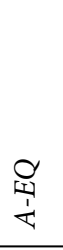 & 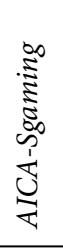 & $\underset{\infty}{\sum_{\infty}^{\infty}}$ & 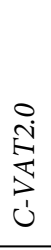 & है & $\mathbb{a}$ & $\underset{J}{\mathbb{S}}$ & $\underset{J}{\mathbb{S}}$ & 憂 & 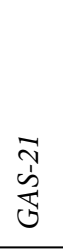 & $\begin{array}{l}\text { ָे } \\
\text { 仓ิ }\end{array}$ & 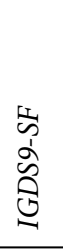 & 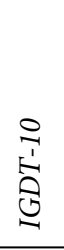 & $\begin{array}{l}\text { 出 } \\
\text { S } \\
0\end{array}$ & 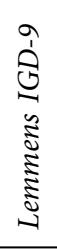 & 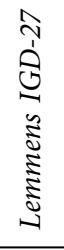 & 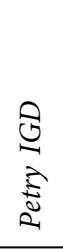 & 点 & $\begin{array}{l}0 \\
0 \\
0 \\
2\end{array}$ & $\begin{array}{l}0 \\
0 \\
0 \\
\&\end{array}$ & $\begin{array}{l}\text { L } \\
\text { d } \\
\text { d } \\
0 \\
2\end{array}$ & $\stackrel{2}{a}$ & తి & 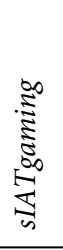 & $\sum_{S}^{0}$ & $\underset{5}{5}$ & $\frac{\pi}{\pi}$ & $\underset{\Xi}{\vdots}$ & $\stackrel{8}{\nexists}$ & 푱 \\
\hline Scope & - & - & - & - & - & - & - & 1 & - & - & - & - & - & - & - & - & - & - & 4 & - & - & - & - & - & 1 & - & - & 2 & - & 8 \\
\hline Language & 2 & 2 & - & - & - & 2 & - & - & - & - & 1 & 1 & - & - & - & - & - & - & 1 & - & - & - & - & - & - & - & - & - & - & 9 \\
\hline Overpathologizing & 1 & - & - & - & 3 & - & 1 & 4 & 1 & 5 & 3 & - & 1 & 1 & 2 & 3 & - & - & 6 & 3 & 2 & 1 & - & 1 & 11 & 2 & 2 & 3 & - & 56 \\
\hline Other & - & - & - & - & - & - & - & - & - & - & 1 & - & - & - & - & - & - & - & - & 1 & 1 & - & - & - & - & 1 & 1 & - & - & 5 \\
\hline Total issues & 3 & 2 & - & - & 3 & 2 & 1 & 4 & 1 & 5 & 5 & 1 & 1 & 1 & 2 & 3 & - & - & 10 & 4 & 3 & 1 & - & 1 & 12 & 3 & 3 & 5 & - & 76 \\
\hline Total items affected & 2 & 2 & - & - & 3 & 2 & 1 & 4 & 1 & 5 & 4 & 1 & 1 & 1 & 2 & 3 & - & - & 8 & 4 & 3 & 1 & - & 1 & 11 & 3 & 3 & 5 & - & 71 \\
\hline Proportion of test* $(\%)$ & 16 & 13 & - & - & 17 & 20 & 6 & 15 & 14 & 18 & 20 & 11 & 10 & 11 & 22 & 11 & - & - & 40 & 22 & 25 & 11 & - & 8 & 52 & 14 & 14 & 25 & - & $17 \%^{\mathrm{a}}$ \\
\hline
\end{tabular}

${ }^{*}$ Number of items with face validity issues/Total test items.

${ }^{a}$ Total Face validity issues/Total items (i.e., 71/417). Total A-EQ: Addiction-Engagement Questionnaire; AICA-Sgaming: Assessment of Internet and Computer Addiction Scale-Gaming; BAM-VG: Behavioral Addiction Measure for Video Gaming (Sanders and Williams, 2016); CSAS: Video Game Dependency Scale; C-VAT 2.0; Clinical - Video Game Addiction Test 2.0; DIA: Diagnostic Interview for Internet Addiction; GAIT: Game Addiction Identification Test; GAIA: Game Addiction Inventory for Adults; GAS-7: Game Addiction Scale-7 items; GAS-21: Game Addiction Scale-21 items; IGD-20: Internet Gaming Disorder-20 Test; IGDS9-SF: Internet Gaming Disorder Scale-9 Short Form; IGDT-10; Internet Gaming Disorder Test-10 items; IGUESS: Internet Game Use-Elicited Symptom Screen; Lemmens IGD-9: Internet Gaming Disorder Scale-9 items; Lemmens IGD-27: Internet Gaming Disorder Scale-27 items; Petry IGD: Petry et al. consensus statement on IGD criteria; PIE-9: Personal Internet Gaming Disorder Evaluation-9 items (Pearcy et al., 2016); POGU: Problematic Online Game Use; POGQ: Problematic Online Gaming Questionnaire; POGQ-SF: Problematic Online Gaming Questionnaire-Short Form; PVP Scale: Problematic Video game Playing Scale; SCI-IGD: Structured Clinical Interview-Internet Gaming Disorder (Koo et al., 2017); sIATgaming: Short Internet Addiction Test-Gaming; VASC: Video Game Addiction Scale for Children; VAT: Video Game Addiction Test; CIUS-14: Compulsive Internet Use Scale-14 items; YIAT: Young Internet Addiction Test; YDQ: Young Diagnostic Questionnaire. 
particularly open-ended and service-based games with unlimited goals and opportunities.

Suggested modifications. Many of these tests may be improved by simply removing certain items, or instead using such items in a new tool that measures the benefits of gaming. Some items may be modified effectively by including an appropriate qualifier that specifies distress or functional impairment (e.g., "Do you prioritize and spend almost all of your time on video games?" rather than "Do you spend much free time on games").

\section{Other Issues}

Another limitation of the reviewed tests was items that refer to relatively mild versions of symptoms or capture behaviors that may be unlikely to reflect true harm. These items may be useful in identifying emerging problematic behaviors (i.e., ensuring the test has sufficient sensitivity to capture a range of problematic behaviors) but may have less utility in a brief test designed to capture GD only. These "low-risk" items may be problematic for a test, in the same way as the "overpathologizing" items, when they are weighted equivalently to items that refer to severe types of behaviors or consequences (e.g., failing school, relationship breakdown). In addition, some items appear to have low thresholds for endorsement (i.e., low item difficulty) due to their wording or scoring approach, such as when individuals who have experienced any instance of the behavior (e.g., once within the last 12 months) would be considered the same as more severe user profiles. For example, the $A-E Q$ refers to "never miss meals" and being "sometimes late" due to gaming. Similarly, the VAT and CIUS refer to "rush through homework", which may be of minor consequence even when occurring frequently, thus this item may capture an opportunity cost rather than true harm (see Delfabbro \& King, 2019).

Some items refer to a component of addiction (e.g., preoccupation, withdrawal, escape) but lack the essential aspects of the description that specify clinical severity. For example, the CSAS, GAIT, IGD-20 and POGU refer to thinking about games at times when "not playing" (NB: response categories of these tests refer to agreement not frequency), which may not capture the phenomena of having constant thoughts or predominantly thinking about games (DSM-5 concept: preoccupation) or the precedence of gaming-related thoughts (e.g., planning, reliving, anticipating) over other non-gaming cognition (ICD-11 concept: escalating priority). Similarly, the POGQ and POGQ-SF refer to "daydreaming" about games, which may not be synonymous with preoccupation.

Along similar lines, the $I G D-9 / 27$ refers to feeling "unsatisfied" and wanting to "play more" and gaming to not "think about annoying things". These terms may potentially capture gaming-related withdrawal (Kaptsis, King, Delfabbro, \& Gradisar, 2016), feelings of inadequacy (King et al., 2018a,b), and a reliance on games for mood relief (Petry et al., 2014). However, these items are scored dichotomously, which may make them too sensitive or easy to endorse (i.e., generate false positives) by capturing gaming experiences typically reported by regular gamers when reflecting on the past year of activities (Colder Carras, Porter, van Rooij, King, Lange, \& Labrique, 2018; Delfabbro \& King, 2019). Another example of oversensitivity is an item that refers to thinking "just a few more minutes" when playing games, which is used in the POGU, sIATgaming, and YIAT20. This item may potentially capture loss of control in some cases, but it may also refer to poor time management skills or procrastination.

Suggested modifications. These tests may be improved by rewording items that refer to GD symptoms to better capture the severity, frequency and duration of behaviors (e.g., see Ko et al. 2019). Minor or temporary negative consequences of gaming could be weighted lower for scoring purposes or relegated to a measure of "emerging/low risk" problematic gaming instead of addiction.

\section{DISCUSSION}

This evaluation found that most items in GD tools demonstrated satisfactory face validity and were consistent with either/both the DSM-5 or ICD-11 classifications. However, many tools contained at least one item that may pathologize normal gaming behaviors. Such items refer to basic changes in mood when gaming, a desire to play or continue playing games, and experiencing immersion when gaming. These issues may relate to the difficulty in adapting concepts from substance-based addictions (e.g., urges, craving, and tolerance) to activities like gaming where changes in hedonic balance are a normal part of the activity. These potential test limitations have implications for scale development in the field of behavioral addictions, which appears likely to expand into new areas following calls for a wider range of repetitive behaviors to be studied (Potenza, Higuchi, \& Brand, 2018). As already flagged by some authors (Billieux et al., 2015; Starcevic, Billieux, \& Schimmenti, 2018), researchers may be inclined to adapt existing measures by substituting keywords to study these conditions, thereby perpetuating these face validity issues in new tests for other behaviors.

These face validity issues may be useful to consider for brief evaluation of other measures, particularly in the field of behavioral addictions where there has been debate on whether some proposed conditions (e.g., online social networking addiction, smartphone addiction) may be overextending or misappropriating the concept of addiction (Billieux et al., 2015). It is noteworthy that this evaluation provided support for the items contained in Petry et al. (2014) IGD measure, which was developed by an international group of 14 experts. These items had also been translated into 10 languages. It may be speculated that this additional attention may have assisted in ensuring that items were adequately aligned with the DSM-5 criteria. 
This review has some noteworthy limitations. It should be emphasized that any items identified in this evaluation may not be problematic psychometrically (i.e., an item identified as "overpathologizing" may actually still perform adequately). This evaluation was based on a small panel of qualified experts; however, these ratings should be considered as justified opinions (e.g., akin to the peer review process). Other raters may not necessarily agree with the panel's determination. For this reason, we have provided all items and our corresponding reasoning in Table 1 for transparency and to enable others to consider and reevaluate. Other limitations of this evaluation were the lack of comparison with available psychometric data for each test (to reduce introducing bias into ratings) and the lack of examination of non-English versions of items. This evaluation also did not account for the typical context and purpose for each test (e.g., use in clinical settings or prevalence studies), which may have introduced some bias, and thus did not account for the constraints and requirements of each context.

On a final note, this review shows that the study of GD has led to a proliferation of tools over time. Many of these instruments are the "same but different" (i.e., similar concepts with slightly different practical execution). Every year since the release of the DSM- 5 in 2013, between 2 and 5 new measures for GD have been created that are mostly similar in length and content to existing ones. Many research teams are working in "silos" by continuing to use and create tools that may not be entirely comparable to each other in some respects. Thus, while the DSM-5 formulation of GD has received strong support and research investment, there is also an isolationist quality to the field's collective epistemic uniformity. It seems difficult in this current situation with so many competing tools to make progress or to turn back. A gold standard tool may help to unify the field and enable, for example, more consistent estimates of prevalence across countries. It is hoped that this review provides some practical avenues to improve current measurement approaches and prompts critical reflection on the essential elements of the formulation of gaming as a potential disorder (King, Koster, \& Billieux, 2019). Finally, in demonstrating that many tests have items that appear to pathologize normal gaming behaviors, this evaluation highlights the challenges of screening effectively for a mental disorder that is thought to arise within the context of a normal recreational activity.

Authors' contributions: The first author designed the review and conducted literature searches and provided summaries of the identified content. The second and third authors contributed to the face validity analysis. The first author wrote the first draft, and all authors contributed to and approved the final manuscript.

Funding: This work received financial support from a Discovery Early Career Researcher Award DE170101198 funded by the Australian Research Council.

Declaration of interest: The authors report no conflicts of interest. The authors alone are responsible for the content and writing of the paper.

\section{REFERENCES}

${ }^{\star}$ Indicates source references for GD tools.

Aarseth, E., Bean, A. M., Boonen, H., Colder Carras, M., Coulson, M., Das, D., et al. (2017). Scholars' open debate paper on the world health organization ICD-11 gaming disorder proposal. Journal of Behavioral Addictions, 6, 267-270.

American Psychiatric Association. (2013). Diagnostic and statistical manual of mental disorders (5th ed.) (DSM-5). Washington, DC: Author.

Bean, A. M., Nielsen, R. K., Van Rooij, A. J., \& Ferguson, C. J. (2017). Video game addiction: The push to pathologize video games. Professional Psychology: Research and Practice, 48, 378389.

Besser, B., Loerbroks, L., Bischof, G., Bischof, A., \& Rumpf, H. J. (2019). Performance of the DSM-5-based criteria for internet addiction: A factor analytical examination of three samples. Journal of Behavioral Addictions, 8, 288-294.

Billieux, J., Flayelle, M., Rumpf, H. -J., \& Stein, D. J. (2019). High involvement versus pathological involvement in video games: A crucial distinction for ensuring the validity and utility of gaming disorder. Current Addiction Reports, 6, 323-330.

Billieux, J., King, D. L., Higuchi, S., Achab, S., Bowden-Jones, H., Hao, W., et al. (2017). Functional impairment matters in the screening and diagnosis of gaming disorder: Commentary on: Scholars' open debate paper on the World Health Organization ICD-11 gaming disorder proposal (Aarseth et al.). Journal of Behavioral Addictions, 6(3), 285-289.

Billieux, J., Schimmenti, A., Khazaal, Y., Maurage, P., \& Heeren, A. (2015). Are we overpathologizing everyday life? A tenable blueprint for behavioral addiction research. Journal of Behavioral Addictions, 4, 119-123.

Brand, M., Young, K. S., Laier, C., Wölfling, K., \& Potenza, M. N. (2016). Integrating psychological and neurobiological considerations regarding the development and maintenance of specific Internet-use disorders: An Interaction of Person-AffectCognition-Execution (I-PACE) model. Neuroscience \& Biobehavioral Reviews, 71, 252-266.

Campbell, S. M., Hann, M., Roland, M. O., Quayle, J. A., \& Shekelle, P. G. (1999). The effect of panel membership and feedback on ratings in a two-round Delphi survey: Results of a randomized controlled trial. Medical Care, 37, 964-968.

${ }^{*}$ Charlton, J. P., \& Danforth, I. D. (2007). Distinguishing addiction and high engagement in the context of online game playing. Computers in Human Behavior, 23, 1531-1548.

Colder Carras, M., Porter, A. M., van Rooij, A. J., King, D. L., Lange, A., \& Labrique, A. J. (2018). Gamers' insights into the phenomenology of normal gaming and game "addiction": A mixed methods study. Computers in Human Behavior, 79, 238-246.

Csikszentmihalyi, M. (1997). Finding flow: The psychology of engagement with everyday life. Basic Books.

Delfabbro, P. H. \& King, D. L. (2019). Challenges in the conceptualisation and measurement of gambling-related harm. Journal of Gambling Studies, 35, 743-755.

${ }^{*}$ Demetrovics, Z., Urbán, R., Nagygyörgy, K., Farkas, J., Griffiths, M. D., Pápay, O., et al. (2012). The development of the 
problematic online gaming questionnaire (POGQ). PLoS One, 7, e36417.

Feng, W., Ramo, D., Chan, S., \& Bourgeois, J. (2017). Internet gaming disorder: Trends in prevalence 1998-2016. Addictive Behaviors, 75, 17-24.

Goodman, A. (1990). Addiction: Definition and implications. British Journal of Addiction, 85, 1403-1408.

Grant, J. E. \& Chamberlain, S. R. (2016). Expanding the definition of addiction: DSM-5 vs. ICD-11. CNS Spectrums, 21, 300-303.

Griffiths, M. D. (2017). Behavioural addiction and substance addiction should be defined by their similarities not their dissimilarities. Addiction, 112, 1718-1720.

Hardesty, D. M. \& Bearden, W. O. (2004). The use of expert judges in scale development: Implications for improving face validity of measures of unobservable constructs. Journal of Business Research, 57, 98-107.

Holloway, L., Humphrey, L., Heron, L., Pilling, C., Kitchen, H., Højbjerre, L., et al. (2014). Patient-reported outcome measures for systemic lupus erythematosus clinical trials: A review of content validity, face validity and psychometric performance. Health and Quality of Life Outcomes, 12, 116.

${ }^{\star}$ Jo, S. J., Yim, H. W., Lee, H. K., Lee, H. C., Choi, J. S., \& Baek, K. Y. (2018). The Internet Game Use-Elicited Symptom Screen proved to be a valid tool for adolescents aged 10-19 years. Acta Paediatrica, 107, 511-516.

Kaptsis, D., King, D. L., Delfabbro, P. H., \& Gradisar, M. (2016). Withdrawal symptoms in internet gaming disorder: A systematic review. Clinical Psychology Review, 43, 58-66.

Kardefelt-Winther, D., Heeren, A., Schimmenti, A., van Rooij, A., Maurage, P., Carras, M., et al. (2017). How can we conceptualize behavioural addiction without pathologizing common behaviours?. Addiction, 112, 1709-1715.

${ }^{\star}$ Kim, M. G. \& Kim, J. (2010). Cross-validation of reliability, convergent and discriminant validity for the problematic online game use scale. Computers in Human Behavior, 26, 389398.

King, D. L. \& Delfabbro, P. H. (2014). Is preoccupation an oversimplification? A call to examine cognitive factors underlying internet gaming disorder. Addiction, 109, 15661567.

King, D. L. \& Delfabbro, P. H. (2019). Internet gaming disorder: Theory, assessment, treatment, and prevention. Cambridge, MA: Elsevier Academic Press.

King, D. L., Delfabbro, P. H., Potenza, M. N., Demetrovics, Z., Billieux, J., \& Brand, M. (2018b). Internet gaming disorder should qualify as a mental disorder. Australian and New Zealand Journal of Psychiatry, 52, 615-617.

King, D. L., Haagsma, M. C., Delfabbro, P. H., Gradisar, M., \& Griffiths, M. D. (2013). Toward a consensus definition of pathological video-gaming: A systematic review of psychometric assessment tools. Clinical Psychology Review, 33, 331-342.

King, D. L., Herd, M. C. E., \& Delfabbro, P. H. (2018a). Motivational components of tolerance in Internet gaming disorder. Computers in Human Behavior, 78, 133-141.

King, D. L., Koster, E., \& Billieux, J. (2019). Study what makes games addictive. Nature, 573, 346.
King, D. L., Chamberlain, S. R., Carragher, N., Billieux, J., Stein, D., Mueller, K., et al. (2020). Screening and assessment tools for gaming disorder: A comprehensive systematic review. Clinical Psychology Review, 77, 101831.

*Király, O., Sleczka, P., Pontes, H. M., Urbán, R., Griffiths, M. D., \& Demetrovics, Z. (2017). Validation of the ten-item internet gaming disorder test (IGDT-10) and evaluation of the nine DSM-5 internet gaming disorder criteria. Addictive Behaviors, 64, 253-260.

Ko, C. H., Lin, H. C., Lin, P. C., \& Yen, J. Y. (2019). Validity, functional impairment and complications related to Internet gaming disorder in the DSM-5 and gaming disorder in the ICD-11. Australian and New Zealand Journal of Psychiatry, 4867419881499. https://doi.org/10.1177/0004867419881499.

${ }^{\star}$ Koo, H. J., Han, D. H., Park, S. Y., \& Kwon, J. H. (2017). The structured clinical interview for DSM-5 internet gaming disorder: Development and validation for diagnosing IGD in adolescents. Psychiatry Investigation, 14, 21-29.

${ }^{\star}$ Lemmens, J. S., Valkenburg, P. M., \& Gentile, D. A. (2015). The Internet gaming disorder scale. Psychological Assessment, 27, 567-582.

Lemmens, J. S., Valkenburg, P. M., \& Peter, J. (2009). Development and validation of a game addiction scale for adolescents. Media Psychology, 12, 77-95.

Lortie, C. L. \& Guitton, M. J. (2013). Internet addiction assessment tools: Dimensional structure and methodological status. Addiction, 108, 1207-1216.

${ }^{\star}$ Meerkerk, G. J., Van Den Eijnden, R. J., Vermulst, A. A., \& Garretsen, H. F. (2009). The compulsive internet use scale (CIUS): Some psychometric properties. CyberPsychology \& Behavior, 12, 1-6.

^Pápay, O., Urbán, R., Griffiths, M. D., Nagygyörgy, K., Farkas, J., Kökönyei, G., et al. (2013). Psychometric properties of the problematic online gaming questionnaire short-form and prevalence of problematic online gaming in a national sample of adolescents. Cyberpsychology, Behavior, and Social Networking, 16, 340-348.

${ }^{\star}$ Pawlikowski, M., Altstötter-Gleich, C., \& Brand, M. (2013). Validation and psychometric properties of a short version of Young's Internet Addiction Test. Computers in Human Behavior, 29, 1212-1223.

${ }^{\star}$ Pearcy, B. T., Roberts, L. D., \& McEvoy, P. M. (2016). Psychometric testing of the personal internet gaming disorder evaluation-9: A new measure designed to assess internet gaming disorder. Cyberpsychology, Behavior, and Social Networking, 19(5), 335-341.

Petry, N. M., Rehbein, F., Gentile, D. A., Lemmens, J. S., Rumpf, H. J., Mößle, T., et al. (2014). An international consensus for assessing internet gaming disorder using the new DSM-5 approach. Addiction, 109(9), 1399-1406.

${ }^{\star}$ Pontes, H. M., Kiraly, O., Demetrovics, Z., \& Griffiths, M. D. (2014). The conceptualisation and measurement of DSM-5 Internet Gaming Disorder: The development of the IGD-20 Test. PLoS One, 9(10), e110137.

${ }^{\star}$ Pontes, H. M. \& Griffiths, M. D. (2015). Measuring DSM-5 Internet gaming disorder: Development and validation of a short psychometric scale. Computers in Human Behavior, 45, 137-143. 
Potenza, M. N., Higuchi, S., \& Brand, M. (2018). Call for research into a wider range of behavioural addictions. Nature, 555,7694 .

Przybylski, A. K., Weinstein, N., \& Murayama, K. (2016). Internet gaming disorder: Investigating the clinical relevance of a new phenomenon. American Journal of Psychiatry, 174, 230-236.

${ }^{\star}$ Rehbein F., Baier D., Kleimann M., Mößle T. Computerspielabhängigkeitsskala (CSAS): Ein Verfahren zur Erfassung der Internet Gaming Disorder nach DSM 5 [Video Game Dependency Scale (CSAS): Assessment of Internet Gaming Disorder based on DSM 5]. Göttingen: Hogrefe; im Druck.

Rumpf, H. -J., Achab, S., Billieux, J., Bowden-Jones, H., Carragher, N., Demetrovics, Z., et al. (2018). Including gaming disorder in ICD-11: The need to do so from a clinical and public health perspective. Journal of Behavioral Addictions, 7, 556-561.

${ }^{\star}$ Ryu, H., Lee, J. Y., Choi, A., Chung, S. J., Park, M., Bhang, S. Y., et al. (2019). Application of diagnostic interview for internet addiction (DIA) in clinical practice for Korean adolescents. Journal of Clinical Medicine, 8, e202.

${ }^{*}$ Salguero, R. A. \& Morán, R. M. B. (2002). Measuring problem video game playing in adolescents. Addiction, 97, 1601-1606.

${ }^{\star}$ Sanders, J. L. \& Williams, R. J. (2016). Reliability and validity of the behavioral addiction measure for video gaming. Cyberpsychology, Behavior, and Social Networking, 19, 43-48.

Saunders, J., Hao, W., Long, J., King, D. L., Mann, K., Fauth-Bühler, M., et al. (2017). Gaming disorder: Its delineation as a serious condition for diagnosis, management and prevention. Journal of Behavioral Addictions, 6, 271-279.

Seok, S., \& DaCosta, B. (2012). The world's most intense online gaming culture: Addiction and high-engagement prevalence rates among South Korean adolescents and young adults. Computers in Human Behavior, 28, 2143-2151.

Snodgrass, J. G., Dengah , II, H. F., Lacy, M. G., Else, R. J., Polzer, E. R., Arevalo, J. M., et al. (2018). Social genomics of healthy and disordered internet gaming. American Journal of Human Biology, 30, e23146.

Sosso, F. E., Kuss, D. J., Vandelanotte, C., Jasso-Medrano, J. L., Husain, M. E., Curcio, G., et al. (2020). Insomnia, sleepiness, anxiety and depression among different types of gamers in African countries. Scientific Reports, 10, 1937.

Starcevic, V. (2017). Internet gaming disorder: Inadequate diagnostic criteria wrapped in a constraining conceptual model: Commentary on: Chaos and confusion in DSM-5 diagnosis of Internet Gaming Disorder: Issues, concerns, and recommendations for clarity in the field (Kuss et al.). Journal of Behavioral Addictions, 6, 110-113.

Starcevic, V., Billieux, J., \& Schimmenti, A. (2018). Selfitis, selfie addiction, Twitteritis: Irresistible appeal of medical terminology for problematic behaviours in the digital age. Australian and New Zealand Journal of Psychiatry, 52, 408-409.

Stein, D. J., Phillips, K. A., Bolton, D., Fulford, K. W. M., Sadler, J. Z., \& Kendler, K. S. (2010). What is a mental/psychiatric disorder? From DSM-IV to DSM-V. Psychological Medicine, 40, $1759-1765$.
Stevens, M. W. R., King, D. L., Dorstyn, D., \& Delfabbro, P. H. (2019). Cognitive-behavioral therapy for internet gaming disorder: A systematic review and meta-analysis. Clinical Psychology and Psychotherapy, 26, 191-203.

*Vadlin, S., Åslund, C., \& Nilsson, K. W. (2015). Development and content validity of a screening instrument for gaming addiction in adolescents: The Gaming Addiction Identification Test (GAIT). Scandinavian Journal of Psychology, 56(4), 458466.

${ }^{*}$ van Rooij, A. J., Schoenmakers, T. M., Van den Eijnden, R. J., Vermulst, A. A., \& van de Mheen, D. (2012). Video game addiction test: Validity and psychometric characteristics. Cyberpsychology, Behavior, and Social Networking, 15, 507511.

*van Rooij, A. J., Schoenmakers, T. M., \& Van de Mheen, D. (2017). Clinical validation of the C-VAT 2.0 assessment tool for gaming disorder: A sensitivity analysis of the proposed DSM-5 criteria and the clinical characteristics of young patients with 'video game addiction'. Addictive Behaviors, 64, 269-274.

Van Rooij, A. J., Ferguson, C. J., Colder Carras, M., KardefeltWinther, D., Shi, J., Aarseth, E., ... \& Deleuze, J. (2018). A weak scientific basis for gaming disorder: Let us err on the side of caution. Journal of Behavioral Addictions, 7, 1-9.

Wang, C. W., Chan, C. L., Mak, K. K., Ho, S. Y., Wong, P. W., \& Ho, R. T. (2014). Prevalence and correlates of video and internet gaming addiction among Hong Kong adolescents: A pilot study. The Scientific World Journal, 2014, Article ID 874648 .

West, R. (2001). Theories of addiction. Addiction, 96, 3-13.

Willis, G. B. (2004). Cognitive interviewing: A tool for improving questionnaire design. Sage Publications.

${ }^{*}$ Wölfling, K., Beutel, M. E., \& Müller, K. W. (2012). Construction of a standardized clinical interview to assess Internet addiction: First findings regarding the usefulness of AICA-S. Addiction Research \& Therapy, 6, 1-7.

Wong, U. \& Hodgins, D. C. (2014). Development of the game addiction inventory for adults (GAIA). Addiction Research \& Theory, 22, 195-209.

World Health Organization (WHO). (2019). 6C51 Gaming disorder. Retrieved online: https://icd.who.int/browse11/l-m/en\#/ http://id.who.int/icd/entity/1448597234.

Xin, M., Xing, J., Pengfei, W., Houru, L., Mengcheng, W., \& Hong, Z. (2018). Online activities, prevalence of internet addiction and risk factors related to family and school among adolescents in China. Addictive behaviors Reports, 7, 14-18.

${ }^{*}$ Young, K. S. (1998a). Caught in the net: How to recognize the signs of internet addiction-and a winning strategy for recovery. John Wiley \& Sons.

*Young, K. S. (1998b). Internet addiction: The emergence of a new clinical disorder. CyberPsychology \& Behavior, 1, 237-244.

*Yılmaz, E., Griffiths, M. D., \& Kan, A. (2017). Development and validation of videogame addiction scale for children (VASC). International Journal of Mental Health and Addiction, 15, 869882.

This is an open-access article distributed under the terms of the Creative Commons Attribution-NonCommercial 4.0 International License (https://creativecommons.org/ licenses/by-nc/4.0/), which permits unrestricted use, distribution, and reproduction in any medium for non-commercial purposes, provided the original author and source are credited, a link to the CC License is provided, and changes - if any - are indicated. 